\title{
FORMAÇÃO PROFISSIONAL E PERFIL DOCENTE DA EDUCAÇÃO PROFISSIONAL E TECNOLÓGICA: UM ESTUDO NO IFTM - CAMPUS PARACATU
}

\author{
T. R. A. SOUZA ${ }^{1}$, J. F. SOUZA ${ }^{2}$ \\ Instituto Federal do Triângulo Mineiro - Campus Paracatu \\ terezinhaaguiar@iftm.edu.br ${ }^{1}$
}

Submetido 28/03/2016 - Aceito 28/02/2018

\section{RESUMO}

Este estudo teve por finalidade analisar a formação profissional e o perfil do docente que atua no Instituto Federal do Triângulo Mineiro - Campus Paracatu. O referencial teórico contemplou diversas concepções teóricas a respeito da formação docente e formação para a educação profissional. Identificou-se que ainda são poucas as pesquisas que tratam especificamente da educação profissional. A metodologia utilizada pautou-se em entrevistas com os docentes, feitas por meio de questionários contendo questões abertas e fechadas. No total foram entrevistados 33 docentes. Constatou-se que em geral o docente que ingressa na instituição pesquisada possui experiência docente anterior. Além disso, percebeu-se a carência dos docentes quanto à formação pedagógica e a discordância de grande parte dos entrevistados quanto à diversidade de modalidades existentes nos Institutos Federais. Os resultados também revelam que a formação pedagógica constitui-se necessária também aos licenciados, devido o fato dos mesmos não considerarem sua formação inicial como suficiente para atuação docente.

PALAVRAS-CHAVE: Formação docente, Educação Profissional, Formação pedagógica.

\section{THE PROFESSIONAL FORMATION AND THE TEACHER TRAINING IN PROFESSIONAL EDUCATION: ANALYSIS IN IFTM - CAMPUS PARACATU}

\begin{abstract}
This paper aims at analysing the professional education and the teacher training and its atuation in IFTM Campus Paracatu. The theoretical referential it was approached about teacher formation and professional education. The methodology was pointed out in teacher's interviews which were made through questionnaires. In total, it was interviewed 33 teachers. It was conclued that, in general the teacher has some professional experience. In addition, it was realized that the teachers need pedagogical formation and they consider which this formation is important for the work's performance. The results show which the pedagogical formation is also important for students' degree courses, because they consider their formation is not enough for functioning in their job.
\end{abstract}

KEYWORDS: Teacher Training, Professional Education, Work. 


\section{INTRODUÇÃO}

Tendo em vista o crescimento econômico e produtivo evidenciado no Brasil nos últimos anos, tem sido cada vez mais frequente a busca por maior qualificação profissional. Devido às rápidas transformações tecnológicas e industriais enfrentadas pela sociedade, torna-se cada vez mais desafiador para o mercado de trabalho a busca por mão-de-obra especializada.

Conforme afirma Sampaio (2013, p. 22) “Para uma economia emergente, um baixo nível de produtividade dos trabalhadores, derivado do baixo nível de educação formal, sob o ponto de vista do crescimento do país, implica em um sério gargalo." Nesse contexto, a partir da necessidade do mercado em obter trabalhadores qualificados, o governo federal implantou os Institutos Federais de Educação, Ciência e Tecnologia que, criados em 2008 pela Lei 11.892, possuem como principal proposta o aumento da qualificação com cursos gratuitos e profissionalizantes em diversas áreas.

Desde a sua implantação, os Institutos Federais tem crescido substancialmente. As políticas de expansão abrangem a criação de novos campus e cursos. Como consequência dessa expansão, a partir do aumento de cursos e vagas, as oportunidades de emprego para a área docente dessas instituições também tem crescido progressivamente.

A respeito da profissão docente, a Lei de Diretrizes e Bases da Educação Nacional, em seu Art. 67 dispõe que "A experiência docente é pré-requisito para o exercício profissional de quaisquer outras funções de magistério, nos termos das normas de cada sistema de ensino" (Lei n. $9.934,1996)$. Isso implica que, de acordo com a legislação vigente, para o exercício da docência é necessário que o profissional possua uma experiência docente anterior ao exercício do seu magistério. Entretanto, o expressivo aumento das ofertas de cursos profissionalizantes, seguido pela crescente demanda por docentes, tem levado muitas instituições a contratarem esses profissionais sem qualquer exigência de uma experiência anterior, sendo que muitos profissionais após concluírem o curso superior já ingressam de imediato na carreira docente. Tal fator contribui para a precarização da necessidade de formação docente para o exercício profissional. Uma vez que esta não é exigida, tem-se a percepção de que a mesma não é necessária à prática da profissão.

A fim de propor soluções para este problema está em pauta uma discussão em diversos Institutos Federais a respeito de capacitação pedagógica para professores que não tiveram essa qualificação em sua formação inicial. Acerca disso, faz-se os seguintes questionamentos: Qual a formação profissional docente da educação profissional e tecnológica? Qual a visão do professor acerca da formação pedagógica? As licenciaturas têm preparado pedagogicamente o aluno para ser professor? Essa formação pedagógica constitui-se apenas como um evento isolado ou é necessário uma formação contínua do docente? 
Tendo em vista esses questionamentos, o presente artigo objetiva analisar a formação docente dos profissionais que atuam na Educação Profissional e Tecnológica (EPT). Para isso, escolheu-se por campo de estudo o Instituto Federal do Triângulo Mineiro (IFTM) - Câmpus Paracatu, situado na cidade de Paracatu, região noroeste de Minas Gerais.

\title{
2 FORMAÇÃO DOCENTE
}

Formação de professores constitui-se um processo cujo objetivo é o desenvolvimento pessoal e profissional do indivíduo, sendo que esse processo envolve os aspectos da dimensão acadêmica, artística, pedagógica e literária, com vistas à valorização do sujeito dessa formação. Além disso, é necessário também considerar a contribuição dessa formação para o desenvolvimento humano (Pivetta, 2006).

\begin{abstract}
"A formação de professores torna-se, assim, elemento fundamental que contribui para a melhoria da qualidade de ensino, pois implica a aquisição de conhecimentos, habilidades e competências que permitem aos professores atuarem no desenvolvimento do ensino, do currículo e da instituição" (Pivetta, p. 18, 2006).
\end{abstract}

Pivetta (2006) ressalta que, a construção do saber docente é um processo complexo que se inicia na formação inicial e se concretiza por meio da prática educativa que se obtém ao longo do exercício da docência. Essa construção e socialização de saberes é obtida através de um trabalho coletivo, onde são estabelecidas relações transversais de autonomia e respeito. Tal ideia pode ser reafirmada nas palavras de Durrive (2011), que destaca que o trabalho não consiste apenas na aplicação de saberes já alcançados, pois no decorrer da atividade humana do trabalho outros saberes são produzidos.

Para Oliveira e Silva (2012) o docente deve atentar-se à responsabilidade de sua profissão, que prepara os alunos para os desafios do mundo do trabalho, além de proporcionar uma formação crítica e cidadã. Dessa forma, faz-se necessário que o docente esteja frequentemente inovando suas práticas e aprimorando seus conhecimentos pedagógicos, engajando-se no processo de uma formação contínua.

Nesse sentido, Seixas, Calabró e Sousa (2017) ressaltam que a formação do professor vai além daquela adquirida apenas na graduação, sendo complementada por pesquisas, discussões ou participações em eventos. Assim, discute-se sobre a formação continuada como um recurso auxiliar à formação docente principal, podendo desenvolver-se em cursos de curta ou longa duração não podendo ser constituída um processo restrito apenas a elementos internos da profissão, sendo necessário um diálogo sistematizado com outras constituições do saber (Marques, 2003).

Para Marques (2003) a formação continuada deve ser atribuição das universidades, que após conduzirem o processo formativo do docente, devem colocar-se também como responsáveis pela formação complementar, fornecendo cursos que aprimorem essa formação, uma vez que 
"Trabalhar com os profissionais deles egressos é, assim, exigência do bom desempenho dos cursos que na universidade os preparam (p. 210)".

\subsection{Os desafios da formação docente}

Para Oliveira e Silva (2012), os problemas no processo formativo do profissional não se apresentam somente nos bachareis, sendo que nas licenciaturas atuais também podem ser observadas a existência do modelo " $3+1$ ", modelo tradicional dos currículos atuais, onde apenas no último ano de formação o aluno inicia o estágio docente. Sendo assim, o problema do bacharel reside no fato de que este torna-se professor sem ter tido qualquer contato anterior com a atividade docente e para os licenciados que tiveram esse contato, percebe-se que este é incipiente demais para uma completude da formação docente.

Para Santos (2013), a formação docente enfrenta um dicotomismo com relação aos objetivos da educação, em que são questionados se essa formação deve estar focada mais no sentido da formação humana ou se deve voltar-se ao desenvolvimento de habilidades consideradas essenciais ao mundo do trabalho. O problema na formação docente reside no fato de muitos envolverem-se com o mundo do trabalho apenas internamente, esquecendo-se das peculiaridades inerentes à profissão, que demandam um profissional atento às necessidades sociais e culturais de seus alunos.

Oliveira e Silva (2012) destacam que a raiz dos problemas da formação docente pode estar na legislação que deixa a cargo das instituições proporcionarem ou não cursos de formação continuada para aqueles que ingressam na carreira docente. É preciso que a legislação seja mais enfática no sentido de cobrar maiores conhecimentos didático-pedagógicos dos profissionais que compõem o quadro docente das instituições.

Carvalho (2012) ressalta que a visão conservadora da ação docente, com aulas expositivas presenciais, que enfatiza a repetição e memorização do conhecimento, não têm sido suficientes para atender os desafios da diversidade de conhecimentos presente nos dias atuais. Em uma sociedade onde a tecnologia está avançando a passos largos, faz-se necessário utilizar-se dos meios eletrônicos como método de ensino. Seixas et al. (2017) ratificam essa ideia quando afirmam que, apesar do livro didático ser o principal instrumento do professor para transmissão de conhecimentos aos alunos, na era tecnológica em que vivemos fazer uso de recursos mais avançados como lousa digital, computadores, mídias dentre outros recursos faz-se essencial para que o professor qualifique o domínio do conteúdo e aprendizado dos alunos.

Macenhan, Tozetto e Brandt (2016) destacam que a inexperiência dos professores recémformados é uma das principais causas das desistências e frustrações com a carreira docente, uma vez que os mesmos não conseguem vivenciar em seu processo formativo a prática docente. Faz-se importante que isso ocorra pois através dessas experiências é que o professor poderá se mobilizar e se preparar para novas situações no ambiente de trabalho. A formação profissional não pode 
estar dissociada da prática pedagógica. Para tanto, é necessário uma constante relação entre a teoria e prática para atuar na docência.

O problema reside em que a docência universitária ainda é pautada no ensino tradicional, o qual não busca atender os novos desafios e exigências do ensino fazendo com que haja uma pouca visibilidade e apropriação dos saberes pedagógicos por parte dos docentes. Ainda, a deficiência encontra-se nos espaços de formação, que não se apropriam dos instrumentos necessários aos saberes docentes e que favorecem o processo ensino-aprendizem (Freitas, et al. 2016).

Além disso, pode-se dizer que a formação docente tem sido precarizada porque muitos professores não se reconhecem como docentes, preferindo serem denominados técnicos (engenheiros, biólogos, químicos, etc). Aliado a esse fato, muitos consideram a carreira docente como uma atividade provisória, enquanto esperam para exercer uma atividade mais ligada à sua área técnica (Araújo, 2008). O fato de muitos pertencerem a conselhos profissionais retrata essa preferência maior à sua área de formação técnica do que a sua formação como docente (Santos, 2013). Esses fatores fazem com que aumente a resistência dos professores no que se refere à inserção dos conhecimentos pedagógicos em sua formação, uma vez que não se identificam com a profissão tendem a considerar essa formação inútil ou cansativa.

Lima e Silva (2012) ressaltam a dificuldade que o bacharel enfrenta quando se encontra na profissão docente, visto que os conhecimentos obtidos na graduação por esses profissionais resumem-se apenas àqueles específicos de sua área de formação. Pelo fato de possuírem um currículo de destaque em sua área de formação, muitos desses profissionais são contratados por instituições de ensino, que esperam do bacharel que essa mesma competência também seja vista na carreira docente, o que nem sempre ocorre, visto se tratar de profissões diferentes. Para os autores, falta aos cursos de bacharelado disciplinas que preparem o aluno também para a carreira docente.

\subsection{Formação docente no âmbito da Educação Profissional e Tecnológica}

A formação docente não tem sido discutida apenas no ensino básico e superior. Devido o crescimento visível da EPT, muito se tem discutido sobre essa formação para tal modalidade de ensino, dando lugar a algumas iniciativas sobre formação docente para a EPT. Exemplo disso foi o VIII Simpósio da série Educação Superior em Debate, realizado em 2006 pelo Instituto Nacional de Estudos e Pesquisas (INEP), cujo tema foi Formação de Professores para a Educação Profissional e Tecnológica. Apesar disso, estes estudos ainda são incipientes, sendo necessário que essa temática seja mais abordada para maior conhecimento a respeito da mesma.

Conforme afirmam Guedes e Sanchez (2017) a formação docente para a educação profissional pauta-se na questão de que atualmente professores licenciados que atuam na educação profissional não estão preparados para tal campo de atuação por não terem trabalhado 
em sua formação aspectos da relação entre trabalho e educação, tendo apenas por base em sua formação acadêmica o ensino médio de caráter propedêutico. Ainda Guedes e Sanchez (2017) afirmam que, para os bachareis a dificuldade está no fato de que os mesmos não possuem formação instrumental didática e pedagógica.

Nesse sentido, Machado (2008) sugere que haja uma formação pedagógica dos docentes da educação profissional e tecnológica com conteúdos que relacionem a educação de modo geral, bem como a educação e trabalho e a educação profissional. A diferença entre essa formação específica para uma formação geral é que naquela serão estudados conteúdos específicos da educação profissional e tecnológica, como por exemplo a legislação, conceitos e paradigmas do currículo da educação profissional, currículo integrado, dentre outros.

De acordo com Machado (2008), o professor da educação profissional tem à sua frente os desafios decorrentes das mudanças ocorridas no mundo do trabalho. Não basta mais ensinar a fazer de uma forma metódica e pragmática. É preciso ensinar levando em conta as inovações tecnológicas existentes no mercado de trabalho, o aumento da exigência de qualidade na produção e nos serviços, além de questões éticas e de sustentabilidade.

Machado (2008) ainda sugere que, para que haja uma máxima proximidade entre o processo de ensino-aprendizagem com o contexto das relações de trabalho, é necessária uma articulação entre as atividades teóricas e práticas, o que pode ser efetivado por meio de dois tempos de estágio, um onde se busca aprimorar o saber docente e em outro na perspectiva do saber técnico/tecnológico.

Segundo Machado (2008), existem hoje algumas alternativas de formação docente para a educação profissional e tecnológica, entretanto, ainda muito limitadas e não conseguem atingir a crescente demanda da profissão. Além disso, tais cursos limitam-se a cursos de pós-graduação, formação a distância e formação em serviço. Ainda são poucas as licenciaturas específicas para isso.

Oliveira e Silva (2012) apresentam em sua pesquisa possíveis caminhos para melhorias na formação de professores, sendo uma delas a ampliação dos espaços de formação docente nos programas de pós-graduação. Segundo as autoras, ainda é muito limitada a formação docente para a Educação Profissional e para o Ensino Superior, uma vez que as licenciaturas tem preparado o docente apenas para a educação básica. Sendo assim, compete aos programas de pósgraduação, especialmente os cursos stricto sensu o desafio de ampliar esses espaços de formação. Entretanto, Marques (2003) afirma que os cursos de pós-graduação não tem preparado adequadamente o docente por estarem se tornando cada dia mais ligados à áreas específicas. Uma vez que os cursos stricto sensu são exigidos como requisito para ingresso como docente em muitas instituições, estes deveriam abordar mais sobre formação docente, bem como as práticas pedagógicas e argumentativas.

Machado (2008) apresenta como uma proposta de melhoria de formação docente uma licenciatura específica para EPT, para que haja uma maior especialização nessa área. Apesar de favorável a essa proposta, Caldas (2004) ressalta que somente a oferta de cursos de licenciatura 
não é suficiente. É necessário que as instituições ofertem também cursos de Pós-Graduação em Educação, especializando-se na educação profissional, além de cursos de extensão e de outras naturezas.

De acordo com Araújo (2008), uma licenciatura específica para a EPT pode não ser a melhor das opções pela diversidade de cursos e áreas temáticas existentes nessas instituições. Ele também não concorda com a criação de cursos de aperfeiçoamento pedagógico para bacharéis. Para o autor, as qualificações em nível de mestrado e doutorado ainda constituem-se a melhor opção.

Quer seja por cursos scrito sensu ou de formação pedagógica complementar, a formação inicial e continuada de docentes da educação profissional deve ser uma estratégia integrante das políticas públicas de educação profissional e dos processos formativos dessas instituições. Além disso, os recursos públicos para essa formação devem ser utilizados de modo prioritário (Araújo, 2008).

\section{METODOLOGIA}

A pesquisa apresenta-se como um trabalho de abordagem quantitativa e qualitativa, sendo utilizado como método de coleta de dados o questionário semiestruturado aplicado aos docentes do IFTM - Campus Paracatu.

O questionário foi composto de vinte e quatro questões, sendo 17 questões fechadas e 7 questões abertas, divididas em 3 partes, sendo a primeira parte contendo questões sobre a formação do docente, uma segunda etapa em que buscou-se saber sobre as experiências profissionais do entrevistado e uma terceira parte onde procurou-se entender as percepções e opiniões do docente quanto à sua formação.

Como amostra da pesquisa foram considerados todos os professores que se dispuseram a responder o questionário, somando 33 entrevistados em um total de 57 docentes. As respostas dos docentes geraram uma planilha no Excel e os dados coletados foram transcritos e expostos em tabelas para melhor visualização dos resultados encontrados.

O IFTM - Campus Paracatu foi criado no ano de 2009 e possui atualmente 582 alunos matriculados nos cursos técnicos. A instituição possui 3 cursos técnicos e 1 tecnólogo, sendo eles: Técnico em Administração, Técnico em Manutenção e Suporte de Computadores, Técnico em Eletrônica e Tecnólogo em Análise e Desenvolvimento de Sistemas. Os cursos técnicos são oferecidos na modalidade Integrado e Concomitante/Subsequente, o que faz com que a instituição possua em seu quadro profissional docentes das áreas propedêuticas e técnicas.

Atualmente o IFTM - Campus Paracatu possui em seu quadro docente 57 professores, sendo 24 licenciados, 28 bacharéis, 04 licenciados e bachareis e 01 tecnólogo. Quanto à formação em pós-graduação, a instituição conta com 16 especialistas, 29 mestres e 5 doutores. 


\section{RESULTADOS E DISCUSSÃO}

A pesquisa foi realizada com 33 professores, sendo 23 do sexo masculino e 10 do sexo feminino, com idade predominante entre 31 e 40 anos. A maioria ingressou na instituição no ano de 2014, mas foram entrevistados professores que estão desde a criação do Campus em 2009. Em sua grande parte, os entrevistados se enquadram no regime de trabalho 40 horas com dedicação exclusiva.

Os dados da pesquisa, conforme exposto na Tabela 1, demonstraram que $97 \%$ dos entrevistados possuem experiência docente anterior à profissão atual. Deste percentual, cerca de 75\% já tiveram alguma experiência no ensino básico e no ensino superior. Quando se trata do ensino profissional essa porcentagem diminui bastante, sendo $35 \%$ os que disseram terem alguma experiência. Para o nível de pós-graduação esse número é menor ainda, sendo apenas $12 \%$ de docentes que responderam já terem ministrado aulas para essa modalidade.

A respeito de outras experiências profissionais, $81 \%$ dos entrevistados afirmaram já terem trabalhado em períodos anteriores ao ingresso na carreira docente, sendo que apenas $23 \%$ trabalharam na sua própria área de formação.

Tabela 1: Sobre a experiência docente

\begin{tabular}{l|c|c}
\hline & Sim & Não \\
\hline $\begin{array}{l}\text { Possui experiência docente anterior } \\
\text { à sua entrada no IF? }\end{array}$ & $97 \%$ & $3 \%$ \\
$\begin{array}{l}\text { Além da docência possui outra } \\
\text { experiência profissional }\end{array}$ & $81 \%$ & $19 \%$ \\
\hline
\end{tabular}

Conforme indica a Tabela 2, no que tange à formação inicial dos docentes pesquisados houve um certo equilíbrio entre licenciados e bachareis, tendo sido entrevistados $48,39 \%$ de bachareis e $41,49 \%$ de licenciados, sendo o restante licenciados e bachareis. Com relação à posgraduação, a maioria do corpo docente entrevistado se dividiu entre especialistas e mestres, tendo pouco percentual de doutores e apenas um entrevistado que relatou não ter nenhum curso de pós-graduação, demonstrando que o corpo docente do Campus em questão têm buscado melhorias em sua qualificação por meio de cursos de pós-graduação.

Tabela 3: Dados da formação do docente

\begin{tabular}{c|c|c|c|}
\hline Licenciado & Bacharel & Licenciado/Bacharel & Tecnólogo \\
\hline $41,94 \%$ & $48,39 \%$ & $9,68 \%$ & $0 \%$ \\
\hline Especialização & Mestrado & Doutorado & Não possui \\
\hline $32,26 \%$ & $51,61 \%$ & $12,90 \%$ & $3,23 \%$ \\
\hline
\end{tabular}


A partir das modalidades de ensino existentes no Campus, constatou-se que a quase totalidade dos docentes entrevistados (97\%) ministram aulas no Ensino Médio Integrado, e grande parte dos mesmos ministram aulas também nos cursos concomitante/subsequente, como apresentado na Tabela 3. Com relação aos programas institucionais, a maior parte dos entrevistados atua em algum programa institucional, divididos entre Pronatec, Etec, UAB e Centro de Idiomas.

Tabela 4: Níveis e programas de atuação docente

\begin{tabular}{c|c|c}
\hline $\begin{array}{c}\text { Ensino Médio } \\
97 \%\end{array}$ & $\begin{array}{c}\text { Concom./Subseq. } \\
65 \%\end{array}$ & $\begin{array}{c}\text { Tecnólogo } \\
26 \%\end{array}$ \\
\hline Pronatec & Etec & UAB/Centro de \\
& & Idiomas \\
$19 \%$ & $10 \%$ & $10 \%$ \\
\hline
\end{tabular}

Conforme ilustrado na Tabela 4, além de atuarem em programas institucionais externos, percebe-se que grande parte dos docentes participa também de alguma atividade interna além da docência, como pesquisa, extensão, comissões, dentre outros, demonstrando que existe um engajamento por parte dos professores em atividades complementares à docência oferecidas pela instituição.

Quando perguntados se fizeram algum curso de formação pedagógica, $61 \%$ dos entrevistados responderam que sim, o que indica que ainda há uma parcela expressiva que não possui nenhum curso relativo a essa área. A maioria dos licenciados entrevistados indicaram como formação pedagógica a própria licenciatura que fizeram. Outros professores relataram que tiveram formação pedagógica em cursos de especialização e aperfeiçoamento. Todos os que responderam terem feito este curso disseram que acreditam que este tem contribuído para a sua atuação docente.

Tabela 5: Sobre a atuação docente

\begin{tabular}{l|c|c}
\hline & Sim & Não \\
\hline $\begin{array}{l}\text { Desenvolve outras atividades } \\
\text { além da docência? }\end{array}$ & $83 \%$ & $17 \%$ \\
$\begin{array}{l}\text { Fez algum curso de formação } \\
\text { pedagógica? }\end{array}$ & $61 \%$ & $39 \%$ \\
\hline
\end{tabular}

Perguntados sobre o motivo pelo qual escolheram serem docentes na EPT as respostas se diversificaram. Alguns relataram atuarem na profissão por ser esta sua formação, para outros o motivo é a estabilidade empregatícia e financeira que o emprego lhes proporciona. Além destas respostas, foi citado pelos entrevistados o prazer em ser professor e atuar no desenvolvimento da 
sociedade, a oportunidade que eles têm na educação profissional de desenvolver pesquisas e projetos e as oportunidades de qualificação que este trabalho lhes proporciona.

Quando questionados se acreditam que a formação pedagógica é relevante para a prática docente a maioria afirmou que sim, apesar de alguns terem dito não entenderem de que se trata a formação pedagógica. Mesmo aqueles que não possuem essa formação ou não conhecem o suficiente sobre ela, disseram que a consideram importante. As justificativas foram diversas, mas o mais visualizado nas respostas foi a associação da pedagogia com a prática docente, ao afirmarem que essa formação lhes proporcionará mais eficiência em sua atuação profissional.

Para os licenciados, foi questionado se a licenciatura os preparou adequadamente para a docência. Para alguns a licenciatura os preparou adequadamente, outros consideram que o curso feito não os preparou para a docência, alegando que só adquiriram essa qualificação com a prática. Todavia, a maioria acredita que a licenciatura não os preparou completamente, mas lhes deu uma base de conhecimentos para atuarem na docência. A principal crítica a essa deficiência foi quanto à prática, tendo em vista que alguns entrevistados disseram que a licenciatura concentra-se muito na teoria, necessitando de bases práticas no decorrer do curso.

A última pergunta feita aos entrevistados foi se, além do conhecimento obtido com sua formação, eles sentiam falta de algo para melhorar a sua atuação docente. As respostas foram as mais variadas, entretanto, predominou entre as respostas os cursos, encontros ou reuniões para discussões pedagógicas. Além disso, também foram citados cursos da própria área e intercâmbio entre professores (do próprio instituto e de instituições diferentes) para troca de experiências e ideias.

\section{CONCLUSÃO}

O mercado de trabalho encontra-se em frequente evolução. As novas exigências mercadológicas demandam um novo profissional, que possua formação multidisciplinar, saiba lidar com as diferentes tecnologias, possua atitudes inovadoras e criativas e esteja em constante qualificação. Tais exigências também perpassam pela profissão docente, sendo que nessa abordagem a necessidade é ainda mais exigida, haja vista o profissional ter em si a responsabilidade de formação de novos profissionais para o mercado de trabalho.

Ao final deste trabalho pode-se chegar a algumas conclusões. Analisando a formação geral dos docentes do Campus Paracatu o que se percebe é que grande parte dos mesmos possuem tanto experiência docente quanto outras experiências profissionais. Esse elemento constitui-se positivo para a instituição no sentido de que o docente ao ingressar no IFTM traz em sua bagagem profissional experiências docentes e técnicas que podem agregar maior valor à sua profissão.

Haja vista a importância da formação pedagógica, verificar que cerca de $40 \%$ dos docentes não possuem essa formação torna-se um elemento a ser discutido com mais intensidade. Além disso, quando se analisa a percepção dos licenciados quanto à sua formação e as respostas dos docentes sobre o que necessitam para melhorarem sua atuação enquanto docente, percebe-se que existe e é visível no professor o anseio por uma qualificação pedagógica. 
A grande associação que estes fazem da formação pedagógica com a prática docente nos faz compreender que o docente entende a formação pedagógica como um elemento bastante presente dentro do contexto da sala de aula, o que pode auxiliá-lo no processo de aceitação de possíveis políticas públicas para essa formação.

Com essa pesquisa, espera-se que a análise feita com os docentes seja uma contribuição aos estudos sobre a formação docente em geral, e especificamente sobre a formação docente para a EPT, na qual ainda existem poucos trabalhos. Para o Campus Paracatu, espera-se que este trabalho sirva como um meio de avaliar as práticas de formação docente existentes e que a partir dessa discussão surjam políticas públicas que auxiliem o docente em seu processo de qualificação.

\section{REFERÊNCIAS}

Araújo, R. M. de L. (2008). Formação de docentes para a educação profissional e tecnológica: Por uma pedagogia integradora da educação profissional. Trabalho \& Educação. 17(2), 31-52.

Carvalho, R. I. B. (2012). A prática pedagógica do bacharel professor da área de comunicação social. Tese de doutorado, Universidade de Brasília, Brasília, DF, Brasil.

Durrive, L. (2011). A atividade humana, simultaneamente intelectual e vital: Esclarecimentos complementares de Pierre Pastré e Yves Schwartz. Trabalho Educação e Saúde. 9(1), 47-67.

Freitas, D. A.; Santos, E. M. S.; Lima, L. V. S.; Miranda, L. N.; Vasconcelos, E. L.; \& Nagliate, P. C. (2016). Saberes docentes sobre processo ensino-aprendizagem e sua importância para a formação profissional em saúde. Interface. 20(57), 437-448.

Guedes, I. A. C; \& Sanchez, L. B. (2017). A formação docente para a educação profissional técnica e sua influência na atuação dos professores do Instituto Federal do Amapá - Campus Macapá: um estudo de caso. Holos. 07(33), 238-252.

Lei no 9.394, de 20 de dezembro de 1996. (1996). Estabelece as diretrizes e bases da educação nacional. Brasília. Recuperado 22 de novembro de 2014, de http://www.planalto.gov.br/ccivil_03/leis/19394.htm

Lima, A. D.; Silva, J. A. (2012). Práticas pedagógicas: os desafios e expectativas de ser professor do ensino superior. An. Sciencult. 4(1), 15-21.

Macenhan, C.; Tozetto, S. S.; \& Brandt, C. F. (2016). Formação de professores e prática pedagógica: uma análise sobre a natureza dos saberes docentes. Práxis Educativa. 11(2), 505-525.

Machado, L. R. de S. (2008). Diferenciais inovadores na formação de professores para a educação profissional. Revista Brasileira de Educação Profissional e Tecnológica, 1, 8-22.

Marques, M. O. (2003). A formação profissional de Educação. ljuí(RS): Editora Unijuí.

Oliveira, V. S.; \& Silva, R. F. (2012). Ser bacharel e professor: dilemas na formação de docentes para a educação profissional e ensino superior. Holos. 2(28), 193-205.

Pereira, L. A. C. (2004). A formação de professores e a capacitação de trabalhadores da educação profissional e tecnológica. Anais do Fórum de Educação Profissional, Brasília, DF.

Pivetta, H. M. F. (2006). Concepções de formação e docência dos professores do curso de fisioterapia do Centro Universitário Franciscano. Dissertação de mestrado, Universidade de Santa Maria, Santa Maria, RS, Brasil.

Sampaio, M. V. D. (2013). Educação Profissional: a expansão recente do IFRN e a absorção local dos egressos no mercado de trabalho. Dissertação de mestrado, Universidade Federal do Rio Grande do Norte, Natal, RN, Brasil. 
Seixas, R. H. M.; Calabró, L.; \& Sousa, D. O. (2017). A formação de professores e os desafios de ensinar Ciências. Revista Thema. 14(1), 289-303.

Santos, A.; Suanno, M. V. R. \& Suanno, J. H. (Org.). (2003). Didática e formação de professores: complexidade e transdisciplinaridade. Porto Alegre: Editora Sulina. 